\title{
RESPONSABILIDADE CIVIL DO PERSONAL TRAINER
}

PERSONAL TRAINER'S CIVIL LIABILITY

FABRÍCIO GERMANO ALVES ${ }^{1}$

MAYARA VÍVIAN DE MEDEIROS ${ }^{2}$

\section{RESUMO}

Este trabalho trata da responsabilidade civil do personal trainer no exercício da profissão de educador físico. Este estudo abrange a incidência do Código Civil, da Lei n 9.696/1998, das Resoluções do CONFEF e demais disposições normativas que regulam a atuação profissional na educação física e sua relação com o instituto da responsabilidade civil. 0 estudo do tema é pertinente considerando o aumento na demanda da prestação de serviços personalizados na área da educação física em busca por uma melhor qualidade de vida e de saúde em geral. 0 objetivo deste trabalho consiste na compreensão da regulamentação do exercício profissional dos educadores físicos no Brasil, especificamente da profissão de personal trainer, construindo um diálogo entre esta e a teoria geral da responsabilidade civil, passando pela avaliação de como esses temas são trabalhados e aplicados pelo Poder Judiciário. A metodologia consiste em pesquisa hipotético-dedutiva, com abordagem qualitativa, propósito descritivo, com o objetivo de propor uma avaliação formativa sobre o tema. Com fundamento no Código de Defesa do Consumidor, conclui-se que o personal trainer responde subjetivamente, quando atuar como profissional liberal, e quando estiver vinculado a uma academia, esta responde objetivamente.

PALAVRAS-CHAVE: Responsabilidade Civil. Educação Física. Personal Trainer. Dano.

\section{ABSTRACT}

This work deals with the civil liability of the personal trainer in the exercise of the physical educator profession. This study covers the incidence of the Civil Code, the Law 9.696/1998, the CONFEF Resolutions and other normative provisions that regulate the professional performance in physical education and its relationship with the institute of civil responsibility. The study of the theme is pertinent considering the increase in the demand for personalized services in the area of physical education in search of a better life quality and health in general. The objective of this work is to understand the regulation of the professional practice of physical education teachers in Brazil, specifically the profession of personal trainer, building a dialogue between this and the civil responsibility general theory, passing through the evaluation of how these issues are handled and applied by the Judiciary. The methodology consists of hypothetical-deductive research, with qualitative approach, descriptive purpose, with the objective of proposing a formative evaluation on the theme. Based on the Consumer Protection Code, it is concluded that the personal trainer responds subjectively, when acting as a liberal professional, and when linked to an academy, it responds objectively.

1 Doutor em Sociedad Democrática, Estado y Derecho pela Universidad del País Vasco / Euskal Herriko Unibertsitatea (UPV/ EHU) - Espanha. Mestre em Direito (UFRN). Especialista em Direito do Consumidor e Relações de Consumo (UNP). Especialista em Docência no Ensino Superior (FMU). Professor da Graduação e Pós-Graduação da UFRN. Advogado. http://orcid. org/0000-0002-8230-0730. fabriciodireito@gmail.com.

2 Graduanda em Direito pela Universidade Federal do Rio Grande do Norte - UFRN. vivi_caico@hotmail.com.

Como citar esse artigo/How to cite this article:

ALVES, Fabrício Germano. MEDEIROS, Mayara Vívian de. Responsabilidade civil do Personal Trainer. Revista Meritum, Belo Horizonte, vol. 15, n. 1, p. 81-94, jan./abr. 2020. DOI: https://doi.org/10.46560/meritum.v15i1.7644. 
KEYWORDS: Civil liability. Physical Education. Personal Trainer. Damage.

\section{INTRODUÇÃO}

A responsabilidade é um dos principais temas de estudo no âmbito do Direito Civil, tendo como base o restabelecimento do equilibro patrimonial e extrapatrimonial decorrentes do dano proveniente das mais variadas espécies de fatos sociais. Entre as muitas atividades exercidas no campo social, a atividade dos educadores físicos em geral é um dos campos do qual pode se originar a existência de danos e prejuízos, acarretando a necessidade de reparação. Esta é essencial no campo social, sendo uma forma de proteger bens jurídicos tutelados pelo Direito, sejam de cunho patrimonial ou direitos relativos à personalidade. Nesse contexto, este trabalho terá como tema principal a responsabilidade civil dos educadores físicos, mais especificamente, do personal trainer em suas atividades típicas.

Nos últimos anos a procura pela carreira de educador físico tem crescido consideravelmente. Segundo dados do Instituto Nacional de Estudos e Pesquisas Educacionais Anísio Teixeira (INEP), no ano de 2015, o número de formandos nos cursos superiores de educação física foi de cerca de 35 mil pessoas $^{3}$. Além disso, a procura por uma melhor qualidade de vida e de saúde em geral, por meio das mais variadas modalidades de atividade física supervisionada é cada vez mais crescente. Em razão da referida atividade ser apoiada por médicos e pela própria mídia percebe-se a importância do estudo da responsabilidade civil no caso de prejuízos físicos, patrimoniais e morais que podem ser causados aos usuários dos serviços prestados pelos educadores físicos, e em especial dos que atuam como personal trainers.

Os procedimentos metodológicos incluem a pesquisa hipotético-dedutiva, com abordagem qualitativa, propósito descritivo, e a finalidade de propor uma avaliação formativa. Serão examinadas de forma direta as normas relacionadas ao tema proposto, incluídas a Lei n 9.696/1998 e as resoluções específicas publicadas pelo Conselho Federal de Educação Física (CREF), como, por exemplo, a Resolução n 307/2015, que dispõe sobre o Código de Ética dos Profissionais de Educação Física, construindo um diálogo entre suas determinações e o instituto da responsabilidade civil. Além disso, será analisado um caso prático atual, a fim de examinar o tratamento dado pelo Poder Judiciário aos conceitos e fatos envolvidos na reparação de danos causados no exercício profissional do personal trainer.

Inicialmente, serão delineados os conceitos que dão base à teoria geral da responsabilidade civil, incluindo os conceitos de responsabilidade civil objetiva e subjetiva, contratual e extracontratual, ato ilícito, abuso de direito, bem como os fundamentos que dão sentido à observância da responsabilidade civil dentro da realidade social.

Em seguida, serão definidos os pressupostos, ou elementos essenciais da responsabilidade civil, ou seja, a conduta humana positiva ou negativa, a culpa genérica do agente, o nexo de causalidade e o dano, ou prejuízo causado.

3 Instituto Nacional de Estudos e Pesquisas Educacionais Anísio Teixeira (INEP). Sinopses Estatísticas da Educação Superior - Graduação. Disponível em: http://portal.inep.gov.br/web/guest/sinopses-estatisticas-da-educacao-superior. Acesso em: 21 set. 2018. 
Posteriormente, será apresentada e analisada a regulamentação do exercício profissional em educação física no Brasil, a partir da Lei n 9.696/1998, da Resolução nº 307/2015 do CONFEF e das demais resoluções expedidas pelo mesmo órgão. Compreender esta matéria é especialmente relevante, pois essas determinações organizam e regulamentam o trabalho dos educadores físicos no país, sendo possível perceber as relações que podem ser estabelecidas entre essa regulamentação e o tema da responsabilidade civil em caso de danos provenientes do exercício profissional do personal trainer.

Por fim, será examinada uma decisão judicial relacionada ao tema, possibilitando a análise da proteção conferida pelo Poder Judiciário aos indivíduos que sofrem prejuízos provenientes do acompanhamento e supervisão dos profissionais de educação física, especialmente no caso dos que atuam como personal trainer.

\section{TEORIA GERAL E PRESSUPOSTOS DA RESPONSABILIDADE CIVIL}

A responsabilidade é um dos principais aspectos da realidade social, representando o dever de restauração do equilíbrio patrimonial e extrapatrimonial decorrente de qualquer atividade que cause danos ou prejuízo, originada nas consequências jurídicas da atividade e no dever não lesar a outrem (STOLZE, 2012, p. 46). A origem do tema está ligada ao Direito Romano, na regulação organizada pelo Estado para compensar os danos causados nas esferas penal e civil, mediante culpa do autor, gerando uma pena e o dever de reparação (TARTUCE, 2017, p. 499).

No caso da responsabilidade civil, sua observância pode se originar do descumprimento obrigacional, desobediência a regras contratuais ou da falta de observância de determinada regra que regula a vida e as relações sociais A responsabilidade civil tem fundamento e está ligada à necessidade da exigência de uma resposta que expressa eficiência, justiça e segurança, contribuindo para a ordem e pacificação social. Por isso o tema da responsabilidade está cada vez mais concentrado no julgamento do dano em si e nas suas consequências, não só na conduta do agente que o causou (GONÇALVES, 2018, p. 30-31).

A doutrina trata da responsabilidade civil a partir de um modelo dual ou binário. Apesar de sua origem distinta, as modalidades de responsabilidade civil estão baseadas na mesma, fonte, que é o contrato social, e no mesmo fato, ou seja, a violação de um dever jurídico preexistente, e obedecem aos mesmos princípios e regras básicas (MARTINS-COSTA, 2003, p. 97).

No ordenamento jurídico brasileiro a responsabilidade civil assumiu status de direito fundamental pela Constituição Federal, sendo reconhecida expressamente no artigo $5^{\circ}$, inciso V ("é assegurado o direito de resposta, proporcional ao agravo, além da indenização por dano material, moral ou à imagem") e no artigo $5^{\circ}$, inciso X ("são invioláveis a intimidade, a vida privada, a honra e a imagem das pessoas, assegurado o direito a indenização pelo dano material ou moral decorrente de sua violação"), que tratam especificamente do direito à indenização por danos patrimoniais e extrapatrimoniais. 
No geral, a responsabilidade civil pode ser classificada em contratual ou negocial e extracontratual ou aquiliana. A primeira decorre do inadimplemento de uma obrigação contratual ou de um negócio unilateral e está regulada nos artigos 389 a 391 do Código Civil 4 . Ela pode originar-se, por exemplo, no descumprimento da obrigação de uma empresa de transportes no sentido de conduzir uma mercadoria em segurança, na hipótese em que a mercadoria fosse parcial ou totalmente destruída em razão de um incidente no transporte. Já na responsabilidade civil aquiliana, não existe vínculo entre a vítima e o causador do dano, estando fundamentada no ato ilícito e no abuso do direito, tratados nos artigos 186 e 187 do Código Civil, respectivamente (GONÇALVES, 2018, p. 45).

Um dos principais institutos que caracterizam a responsabilidade civil extracontratual é o ato ilícito, tratado no artigo 186 do Código Civil ${ }^{5}$. Este pode ser entendido como sendo qualquer ato ou conduta humana que viola direitos subjetivos e privados, ferindo a ordem jurídica e causando danos a outrem. É um fato jurídico em sentido amplo, gerando o dever de reparação e indenização, seja no âmbito civil, penal ou administrativo, como demonstrado no artigo 927 do Código Civil (BRASIL, 2002).

Já o abuso do direito, que também fundamenta a responsabilidade civil extracontratual está previsto no artigo 187 do Código $\mathrm{Civil}^{6}$, sendo um ato jurídico que tem objeto lícito, mas que ao ser praticado de maneira exagerada, acarreta consequências consideradas ilícitas, violando princípios como o da eticidade, socialidade, boa-fé e bons costumes (FRANÇA, 1977, p. 45).

A responsabilidade civil também pode ser classificada como objetiva ou subjetiva. A subjetiva está baseada na comprovação da culpa do autor do dano, sendo, desta forma, indenizável. Já a objetiva existe nas possibilidades legais em que o dano precisa ser reparado independentemente da existência de culpa, sendo necessário apenas a existência do dano e do nexo de causalidade. A responsabilidade objetiva está presente em diversos artigos do Código Civil, como por exemplo os artigos 936 e 937, que tratam da responsabilidade do dono do animal e do dono do prédio em ruína, como também nos artigos 12 e 14 do Código de Defesa do Consumidor (Lei Federal n 8.078/90). Está baseada na teoria do risco, cuja ideia é a de que toda pessoa que exerce uma atividade assume os riscos de danos a terceiros provenientes desta, sendo obrigada a repará-los, mesmo se não houver culpa (GAGLIANO; PAMPLONA FILHO, 2012, p. 201).

Não existe consenso a respeito dos elementos essenciais da responsabilidade civil ou do dever de reparação e indenização. Porém, no geral, são considerados quatro elementos: a conduta ou ação humana, a culpa genérica do agente, o nexo de causalidade, e o dano ou prejuízo causado.

4 Art. 389. Não cumprida a obrigação, responde o devedor por perdas e danos, mais juros e atualização monetária segundo índices oficiais regularmente estabelecidos, e honorários de advogado. Art. 390. Nas obrigações negativas o devedor é havido por inadimplente desde o dia em que executou o ato de que se devia abster. Art. 391. Pelo inadimplemento das obrigações respondem todos os bens do devedor.

5 Art. 186. Aquele que, por ação ou omissão voluntária, negligência ou imprudência, violar direito e causar dano a outrem, ainda que exclusivamente moral, comete ato ilícito.

6 Art. 187. Também comete ato ilícito o titular de um direito que, ao exercê-lo, excede manifestamente os limites impostos pelo seu fim econômico ou social, pela boa-fé ou pelos bons costumes.

7 Art. 936. 0 dono, ou detentor, do animal ressarcirá o dano por este causado, se não provar culpa da vítima ou força maior. Art. 937. O dono de edifício ou construção responde pelos danos que resultarem de sua ruína, se esta provier de falta de reparos, cuja necessidade fosse manifesta. 
O pressuposto da conduta humana diz respeito a uma ação ou omissão, proveniente de qualquer pessoa, que cause danos a outrem. Ou seja, o dano pode ser causado por uma conduta positiva ou negativa, voluntaria ou proveniente de negligência, imprudência ou imperícia, caracterizando o dolo ou culpa stricto sensu. Para que a conduta negativa seja caracterizada é preciso a demonstração de que determinada conduta, configurada como dever jurídico que evitaria o dano, não foi praticada. Por exemplo, o artigo 938 do Código Civil $^{8}$ determina que o habitante do prédio do qual caem coisas responde pelos danos causados, uma vez que há uma presunção de que poderiam ser evitados a partir de uma conduta positiva que deixou de ser praticada pelo agente (GONÇALVES, 2017, p. 65).

A culpa genérica ou lato sensu, abrange o dolo e a culpa stricto sensu. 0 dolo envolve a vontade do agente em ferir o direito de outrem, na intenção de prejudicar. Na responsabilidade civil, o dolo recebe o mesmo tratamento da culpa grave ou gravíssima, gerando o dever de indenização. Já a culpa stricto sensu decorre da inobservância de um dever jurídico já existente, não sendo necessária a violação intencional, e pode se originar da falta de diligência do agente causador do dano, de negligência, imprudência ou imperícia (TARTUCE, 2017, p. 522).

O nexo de causalidade é o elemento imaterial da responsabilidade civil, ligando diretamente a conduta humana ao dano causado em uma relação de causa e efeito. Constitui o elo entre a ofensa ao direito e o prejuízo sofrido. Assim, o fato lesivo se origina na ação ou é consequência previsível desta. A existência do nexo de causalidade é elemento obrigatório para que haja o dever de indenizar (PEREIRA, 1994, p. 75).

Por fim, o dano é o elemento essencial, o fato jurídico que desencadeia a responsabilidade civil. Esta resulta da comprovação do prejuízo, da lesão a um bem jurídico, seja de cunho patrimonial ou extrapatrimonial. Sem ele, não há objeto para reparação no âmbito civil. $\mathrm{O}$ dano pode ser moral, recaindo sobre a honra, nome pessoal ou da família, causando sofrimento ao ofendido, ou patrimonial, quando tem repercussão na realidade financeira deste (FARIAS; ROSENVALD; BRAGA NETTO, 2017, p. 235).

\section{REGULAMENTAÇÃO DA ATIVIDADE PROFISSIONAL EM EDUCAÇÃO FÍSICA E SEU CÓDIGO DE ÉTICA}

No Brasil, o trabalho do profissional de educação física passou a ser regulamentado a partir da vigência da Lei $n^{\circ}$ 9.696, de 1 de setembro de 1998, promulgada após intenso debate por parte de estudiosos e profissionais, tendo como objetivo a organização do exercício profissional do educador físico e a criação do Conselho Federal de Educação Física (CONFEF). Antes da promulgação desta lei, desde a década de 1940, vinha sendo discutida a necessidade da regulamentação da profissão de educação física no Brasil por meio de encontros e debates entre estudantes, estudiosos e diretores de instituições de ensino, visando sua 
organização e a proteção e valorização dos profissionais que atuam na área (SOUSA NETO et. al, 2004, p. 123).

0 artigo $1^{\circ}$ da Lei $n^{\circ} 9.696 / 1998$ definiu limites quanto aos sujeitos que poderiam atuar na área da educação física, restringindo tal atuação exclusivamente a aqueles que estiverem regularmente registrados nos Conselhos Regionais de Educação Física (CREFs) ${ }^{9}$. Esta limitação tinha como objetivo a proteção do mercado de trabalho dos educadores físicos, já que muitas pessoas sem formação na área atuavam como tais, diminuindo a qualidade dos serviços e aulas fornecidas por estes indivíduos sem formação superior e específica (BRASIL, 1998).

Para ser inscrito nos Conselhos Regionais de Educação Física é necessário, segundo o artigo $2^{\circ}$ da referida lei, possuir diploma obtido em curso superior de educação física, oficialmente autorizado ou reconhecido, ou possuir diploma de educação física expedido por instituição de ensino superior estrangeira válido no território nacional. Além disso, o inciso III do artigo $2^{\circ}$ determinou que os que já exerciam atividades próprias de profissionais de educação física até a vigência da lei também podiam ser inscritos nos Conselhos Regionais de Educação Física (BRASIL, 1998) ${ }^{10}$. Ou seja, esses últimos poderiam receber do CONFEF uma autorização para continuar trabalhando, como uma medida de transição entre dois estados jurídicos, respeitando o direito já adquirido por estes trabalhadores nessa fase de adaptação (ALMEIDA; GUTIERREZ, 2008).

As atribuições dos profissionais de educação física estão elencados no artigo $3^{\circ}$ da Lei $n^{\circ}$ 9.696/1998, que se trata de um rol taxativo, envolvendo funções como planejar, supervisionar, organizar, executar e avaliar trabalhos, programas e projetos, bem como prestar serviços de consultoria, assessoria, planejar treinamentos personalizados e específicos, além da participação na divulgação de informações técnicas, científicas e pedagógicas na área das atividades físicas e desportos (BRASIL, 1998) ${ }^{11}$. Dessa forma, o profissional de educação física pode atuar como especialista nos mais variados tipos de exercícios físicos, desde a ginástica, passando pelas lutas em suas várias categorias, danças, musculação, reabilitação, ergonomia, ioga, entre outras, sejam atividades organizadas em grupo ou supervisionadas de maneira individual.

Nesse sentido, é importante salientar que a limitação dos sujeitos que têm autorização para exercer as atribuições de educadores físicos não teve efeitos apenas sobre a proteção desses profissionais, mas também contribuiu para o aumento da qualidade na prestação de serviços e no exercício de atividades relacionadas, decorrente do conhecimento mais aprofundado e da preparação mais efetiva que se espera que os possuidores de cursos de formação tenham, gerando resultados mais satisfatórios e evitando riscos e possíveis danos para

9 Art. 1o. O exercício das atividades de Educação Física e a designação de Profissional de Educação Física é prerrogativa dos profissionais regularmente registrados nos Conselhos Regionais de Educação Física.

10 Art. $2^{\circ}$. Apenas serão inscritos nos quadros dos Conselhos Regionais de Educação Física os seguintes profissionais: I - os possuidores de diploma obtido em curso de Educação Física, oficialmente autorizado ou reconhecido; II - os possuidores de diploma em Educação Física expedido por instituição de ensino superior estrangeira, revalidado na forma da legislação em vigor; III - os que, até a data do início da vigência desta Lei, tenham comprovadamente exercido atividades próprias dos Profissionais de Educação Física, nos termos a serem estabelecidos pelo Conselho Federal de Educação Física.

11 Art. $3^{\circ}$. Compete ao Profissional de Educação Física coordenar, planejar, programar, supervisionar, dinamizar, dirigir, organizar, avaliar e executar trabalhos, programas, planos e projetos, bem como prestar serviços de auditoria, consultoria e assessoria, realizar treinamentos especializados, participar de equipes multidisciplinares e interdisciplinares e elaborar informes técnicos, científicos e pedagógicos, todos nas áreas de atividades físicas e do desporto. 
a saúde daqueles cujas atividades estão sendo mediadas por um educador físico (FREIRE; VERENGUER; COSTA REIS, 2002, p. 42-44).

Dentre as atividades desenvolvidas pelos profissionais de educação física, está o trabaIho do personal trainer, termo original em inglês já incorporado ao cotidiano brasileiro, que é utilizado para identificar um educador físico que oferece supervisão, orientação e acompanhamento individual e adaptado, na busca por objetivos baseados na necessidade ou desejos por parte do usuário em relação à sua saúde ou condicionamento físico. Este trabalho é construído por meio de treinos específicos que levam em conta as capacidades e limitações de cada aluno, dando-Ihe segurança e a possibilidade de resultados mais rápidos e eficientes. Para o exercício dessa atividade, é obrigatório o registro nos CREFs e a formação adequada, garantindo a qualidade na prestação dos serviços e diminuição de riscos provenientes de orientação e acompanhamento inadequados.

Uma das principais determinações da Lei n 9.696/1998 foi a criação do Conselho Federal de Educação Física, que foi estabelecida como uma entidade administrativa, sem fins lucrativos, responsável pela regulamentação profissional dos educadores físicos, dando poderes a esta autarquia para determinar as maneiras pelas quais os profissionais de educação física devem ser formados, garantir seus direitos de exclusividade de atuação na área, orientando, disciplinando e fiscalizando o exercício da atividade profissional (BRASIL, 1998) ${ }^{12}$.

Desde sua criação, o CONFEF editou diversas resoluções sobre o tema, como por exemplo a Resolução n 045/2002, que dispõe sobre a organização de cursos para os profissionais não formados, e a Resolução n 46/2002, que trata da intervenção dos educadores físicos na organização e supervisão de atividades educacionais no ensino básico (CONFEF, 2002; ALMEIDA; GUTIERREZ, 2008).

Uma das principais disposições normativas do CONFEF nos últimos anos é a Resolução n 307, de 9 de novembro de 2015, que dispõe sobre o Código de Ética dos Profissionais de Educação Física registrados no Sistema CONFEF/CREFs. A partir da análise do preâmbulo do Código de Ética, fica claro que este foi elaborado a partir da consciência do papel social e educacional que os educadores físicos possuem, e da necessidade de aperfeiçoamento e adaptação dos profissionais às complexidades envolvidas na realização individual, social e coletiva daqueles que se beneficiam de seu trabalho. Sua criação levou em conta a Declaração Universal dos Direitos Humanos e da Cultura; a Agenda 21, que enfatiza a proteção do meio ambiente nas relações humanas; e a Carta Brasileira de Educação Física de 2000, em seu cuidado com os riscos que podem existir sobre a natureza, a sociedade e a saúde do indivíduo (CONFEF, 2015).

A elaboração do Código de Ética dos Profissionais de Educação Física teve como objetivo garantir o exercício da profissão de maneira competente e qualificada, visando uma melhor qualidade de vida para todos os envolvidos em sua manifestação, sejam os beneficiários, que utilizam os serviços profissionais, ou seu destinatário (o próprio educador físico), nos termos do artigo $2^{\circ}$ da Resolução $n^{\circ} 307 / 2015^{13}$. Dessa forma, o referido Código estabelece, nos artigos $4^{\circ}$ e $5^{\circ}$, os princípios e diretrizes do exercício profissional na área; nos artigo $6^{\circ}$ a $9^{\circ}$, as responsabilidades e os deveres envolvidos; nos artigos 10 e 11, os direitos e benefí- 
cios dos educadores físicos; e por fim, no artigo 12, as infrações e penalidades em caso de violação às determinações do Código de Ética (CONFEF, 2015).

Os princípios que guiam o exercício do profissional de educação física dispostos no artigo $4^{\circ}$, incisos I, II, VII e VIII do Código de Ética são: o respeito à vida, à dignidade e à integridade do indivíduo, a responsabilidade social, a prestação de serviços de maneira responsável e honesta, bem como a atuação dentro de sua identidade e atribuições específicas do seu campo profissional, levando em consideração o papel social do educador físico e os efeitos de sua atividade sobre a qualidade de vida dos beneficiários (CONFEF, 2015).

Dentre as responsabilidades do profissional de educação física previstas no Código de Ética, destacam-se os incisos III, IV e V do artigo $6^{\circ}$, que determinam que os educadores devem prestar serviço e orientação seguros para o beneficiário, baseados no conhecimento educacional adquirido em seus cursos de formação, que traga benefícios à saúde e evite riscos, agindo com responsabilidade, inclusive advertindo o usuário acerca de quaisquer perigos envolvidos na atividade realizada, conforme o inciso VI do mesmo artigo e inciso I do artigo $5^{\circ}$. No inciso XIV do artigo $6^{\circ}$, fica clara a determinação de que o profissional de atividade física deve responsabilizar-se por faltas cometidas durante o exercício de sua atividade, seja de maneira coletiva ou individual. No artigo $7^{\circ}$, inciso I ficou determinado que o educador físico não pode contratar serviços que possam causar danos morais para seu beneficiário ou até para si mesmo, ou incorrer em erro que revele falta de capacidade profissional (CONFEF, 2015).

Em caso de violações às determinações do Código de Ética, segundo os artigos 12 e 14 do mesmo, o profissional de educação física pode sofrer penalidades por parte das Comissões de Ética, das Juntas de Instrução e Julgamento, dos Tribunais Regionais de Ética e do Tribunal Superior de Ética do sistema CONFEF ou CREFs. As penalidades envolvem advertência, censura pública, suspensão do exercício da profissão e até mesmo o cancelamento do registro profissional juntamente com a publicidade do fato que originou a penalidade (CON$\mathrm{FEF}, 2015)^{14}$. O trabalho dos educadores físicos, em especial do personal trainer, envolve o risco de acidentes com seus alunos, em especial as lesões, que podem causar danos patrimoniais e extrapatrimoniais ao aluno, decorrentes de imprudência, imperícia ou negligência por parte do educador físico. Neste caso, o personal trainer deve ser responsabilizado, reparando os danos causados (OLIVEIRA, SILVA, 2005, p. 4; CONFEF, 2000).

A atividade do personal trainer geralmente está ligada à responsabilidade contratual, quando este se encarrega de cumprir o que foi pactuado com seus alunos, na elaboração, supervisão e acompanhamento das variadas modalidades de atividades físicas, visando os objetivos desejados e necessários a cada aluno. Quando se tratar de relação de natureza civil, se ele não cumprir com seu dever, pode responder pelos danos causados, conforme o artigo 475 do Código Civil ${ }^{15}$.

14 Art. 12 - 0 descumprimento do disposto neste Código constitui infração ética, ficando o infrator sujeito a uma das seguintes penalidades, a ser aplicada conforme a gravidade da infração: I - advertência escrita, com ou sem aplicação de multa; II censura pública; III - suspensão do exercício da Profissão; IV - cancelamento do registro profissional e divulgação do fato. Art. 14 - As Comissões de Ética, as Juntas de Instrução e Julgamento, os Tribunais Regionais de Ética e o Tribunal Superior de Ética são órgãos do Sistema CONFEF/CREFs com suas áreas de abrangência e competências elencadas no Código Processual de Ética do Sistema CONFEF/CREFs.

15 Art. 475. A parte lesada pelo inadimplemento pode pedir a resolução do contrato, se não preferir exigir-lhe o cumprimento, cabendo, em qualquer dos casos, indenização por perdas e danos. 
Na maioria dos casos, a relação jurídica existente entre o personal trainer e o aluno beneficiário de seus serviços é de natureza consumerista, pois o serviço constitui atividade ofertada no mercado de consumo d emolde a atender às suas necessidades (FILOMENO, 2018, p. 44), mediante remuneração (serviço) ${ }^{16}$, pelo profissional da educação física (fornecedor) ${ }^{17}$, a uma pessoa física na qualidade de destinatária final (consumidor) ${ }^{18}$. Assim, nos termos da legislação consumerista, tem-se as seguintes hipóteses que implicarão em diferentes resultados no que diz respeito à responsabilização deste profissional: a) o personal trainer atua como profissional liberal, ou seja, sem vinculação a nenhuma academia ou qualquer outra modalidade de atividade empresarial; b) o personal trainer é empregado ou simplesmente presta serviço em nome de uma academia ou entidade análoga.

Na primeira hipótese a responsabilidade será subjetiva, ou seja, a responsabilidade pessoal do personal trainer somente será apurada mediante a verificação de culpa lato sensu (artigo 14, § $4^{\circ}$ do $\left.C D C\right)^{19}$. Na segunda hipótese, contudo, a academia ou instituição análoga será responsabilizada objetivamente, isto é, independentemente da existência de culpa lato sensu (artigo 14, caput, $\mathrm{CDC}^{20}$ ).

A responsabilidade civil do personal trainer também advém da disposição presente no artigo 186 do Código Civil ${ }^{21}$, pois os atos lesivos também são entendidos como atos ilícitos, que violam o direito de outrem, podendo causar prejuízos físicos ou psíquicos, inclusive com repercussões patrimoniais. Na qualidade de ilícito, quando ele for cometido no contexto de uma relação de consumo passará a ser tratado como prática abusiva, nos termos do artigo 39 do CDC (rol exemplificativo) ${ }^{22}$.

Em qualquer hipótese, independente da atividade ser ou não prestada no contexto de uma relação de consumo, é necessário todo cuidado por parte do treinador pessoal com a integridade física e psíquica do beneficiário, evitando acidentes (v.g., nos aparelhos de musculação com anilhas e pesos), bem como prezar pela saúde do aluno, não indicando o uso de substâncias que podem prejudicar sua saúde (v.g., anabolizantes) (ALMEIDA et. al., 2007).

É possível assim perceber a responsabilidade envolvida no exercício da atividade profissional de educação física, que têm efeitos diretos sobre a saúde e bem estar dos beneficiários, que em caso de erro, má execução de determinado exercício ou utilização imprópria de equipamento, falta de acompanhamento ou orientação adequada, entre outros, pode acarretar em danos físicos temporários ou permanentes à saúde ou mesmo atentar contra a própria vida.

16 Art. $3^{\circ}, \S 2^{\circ}$. Serviço é qualquer atividade fornecida no mercado de consumo, mediante remuneração, inclusive as de natureza bancária, financeira, de crédito e securitária, salvo as decorrentes das relações de caráter trabalhista.

17 Art. $3^{\circ}$, caput. Fornecedor é toda pessoa física ou jurídica, pública ou privada, nacional ou estrangeira, bem como os entes despersonalizados, que desenvolvem atividade de produção, montagem, criação, construção, transformação, importação, exportação, distribuição ou comercialização de produtos ou prestação de serviços.

18 Art. $2^{\circ}$, caput. Consumidor é toda pessoa física ou jurídica que adquire ou utiliza produto ou serviço como destinatário final.

19 Art. $14, \S 4^{\circ}$. A responsabilidade pessoal dos profissionais liberais será apurada mediante a verificação de culpa.

20 Art. 14. O fornecedor de serviços responde, independentemente da existência de culpa, pela reparação dos danos causados aos consumidores por defeitos relativos à prestação dos serviços, bem como por informações insuficientes ou inadequadas sobre sua fruição e riscos.

21 Art. 186. Aquele que, por ação ou omissão voluntária, negligência ou imprudência, violar direito e causar dano a outrem, ainda que exclusivamente moral, comete ato ilícito.

22 Art. 39. É vedado ao fornecedor de produtos ou serviços, dentre outras práticas abusivas: [...]. 


\section{A RESPONSABILIDADE CIVIL DO PERSONAL TRAINER NA JURISPRUDÊNCIA NACIONAL}

O exame da jurisprudência atual contribui de maneira fundamental para o entendimento da maneira pela qual o tema da responsabilidade civil decorrente dos serviços prestados pelos educadores físicos está sendo trabalhada na prática, bem como a proteção que pode ser conferida aos que sofrem danos provenientes dessas atividades. Trata-se de um tema que raramente tem chegado aos Tribunais brasileiros. Nesse contexto de escassez, destacam-se as decisões que serão analisadas a seguir, que podem contribuir para o debate em razão da relação com o assunto.

Neste sentido, será analisado um caso julgado pelo Tribunal de Justiça de Santa Catarina (TJSC, 2014), no qual, na petição inicial o autor afirmou que, por não ter sido auxiliado pelo treinador na prática do exercício denominado "supino reto", nem ter recebido socorro imediato do professor e proprietário da academia, não suportou o peso e a barra de ferro caiu sobre seu peito, causando danos à sua saúde. Além disso, afirmou que, após o acidente, o instrutor da academia o ofendeu, causando-Ihe ainda mais constrangimento. Sustentando estarem demonstrados os danos sofridos o autor pediu sua compensação por meio de indenização por danos morais, bem como a aplicação da inversão do ônus da prova, baseado no artigo $6^{\circ}$, inciso VIII do Código de Defesa do Consumidor ${ }^{23}$.

Na sentença o julgador reconheceu que não cabia o pedido de indenização por danos morais realizado contra a academia, interposto pelo autor da ação, entendendo que era de sua responsabilidade o encargo probante (também não acatou a solicitação de inversão do ônus da prova). Ainda que, não tendo sido comprovada a ocorrência de um ilícito, baseado no artigo 186 do Código Civil, não havia fundamento para a reparação dos prejuízos morais alegados pelo autor, o que também foi aplicado à alegação quanto as ofensas verbais que o autor afirmou terem sido dirigidas ao mesmo pelo instrutor e proprietário da academia. $\mathrm{Na}$ sentença em primeira instância não foi reconhecida relação de consumo. Conclui-se que o instrutor da academia não teria a obrigação de estar presente no momento exato do acidente por não ser um treinador exclusivo ou pessoal, e que ao autor da ação competia aguardar a disponibilidade deste, não podendo atribuir a ele a responsabilidade pelo dano sofrido.

Em sede de apelação foi mantida a decisão proferida na sentença, entendendo que houve culpa exclusiva do consumidor quando utilizou o equipamento de musculação com peso acima do que poderia suportar, sem esperar pela ajuda profissional do treinador, rompendo o nexo causal e afastando o dever de indenizar do prestador de serviços, baseado no artigo 14 do Código de Defesa do Consumidor. Apenas em segunda instância foi reconhecida a natureza consumerista da relação. Ainda assim, a inversão do ônus da prova foi considerada inviável, o pleito foi rejeitado e a sentença foi confirmada.

O caso citado não se refere diretamente ao trabalho do personal trainer, mas é importante analisar alguns aspectos que guardam ligações com o tema deste trabalho. Quando o julgador de primeira instância conclui que o instrutor da academia não tinha o dever de

23 Art. $6^{\circ}$ São direitos básicos do consumidor: [...] VIII - a facilitação da defesa de seus direitos, inclusive com a inversão do ônus da prova, a seu favor, no processo civil, quando, a critério do juiz, for verossímil a alegação ou quando for ele hipossuficiente, segundo as regras ordinárias de experiências. 
acompanhar de perto o autor da ação de maneira individual, ele faz referência ao trabalho do personal trainer, o que demonstra que no caso deste, ele haveria de ser responsabilizado por um dano equivalente, já que se trata de atividade de acompanhamento específico, direto e individualizado.

O personal trainer tem a atribuição e o dever de fazer a supervisão, acompanhamento e apoio de maneira adaptada às capacidades e limitações do beneficiário, e por isso no caso de acidentes, ele tem o dever de reparar os danos sofridos por aquele que estiver sob suas ordens e supervisão, como profissional e prestador de serviços em uma relação de consumo (ALMEIDA et.al., 2007). Essa responsabilidade deve ser apurada subjetivamente, ou seja, torna-se imprescindível a comprovação da culpa lato sensu (negligência, imprudência ou imperícia).

Outro caso a ser observado foi julgado pela $1^{\text {a }}$ Turma Recursal do Tribunal de Justiça do Paraná (TJPR, 2015). Na petição inicial, interposta no Juizado Especial da Comarca de Foz do Iguaçu, a autora afirmou que celebrou um contrato de prestação de serviços com o requerido, que trabalharia como seu treinador físico pessoal três vezes por semana, com a duração de uma hora por aula, pagando as mensalidades contratadas, mas este se negou a prestar os serviços, solicitando a autora que se retirasse de seu estabelecimento. A autora então ajuizou ação com pedido de indenização por danos morais, que foi julgada improcedente pela primeira instância.

Em sede de recurso a autora reafirmou a ocorrência de danos morais e o descumprimento contratual, requerendo a aplicabilidade do Código de Defesa do Consumidor (CDC). 0 recorrido, em sua defesa, afirmou que o descumprimento contratual se deu por atrasos por parte da autora, o que, segundo a avaliação dos julgadores do recurso, não foi devidamente comprovado. 0 Tribunal reconheceu a configuração da relação jurídica de consumo, e ainda considerou que houve recusa e falha na prestação dos serviços acordados com o treinador físico, configurando a prática abusiva definida no artigo 39, inciso II do $\mathrm{CDC}^{24}$, ou seja, a recusa no atendimento da demanda da consumidora, apesar de sua disponibilidade e do acordo ajustado, justificando a reparação por danos morais. Na Turma Recursal, por maioria de votos, os julgadores conheceram e deram provimento ao recurso, reformando a sentença inicial.

Em ambas as decisões analisadas a natureza consumerista da relação de prestação de serviço por parte do personal trainer ao aluno beneficiário foi reconhecida (em uma delas esse reconhecimento não ocorreu na primeira instância), o que atrai para a regulamentação da mesma, especialmente na seara da responsabilidade civil, além dos princípios e disposições gerais previstas no Código Civil, as disposições especificas instituídas pelo Código de Defesa do Consumidor.

24 Art. 39. É vedado ao fornecedor de produtos ou serviços, dentre outras práticas abusivas: II - recusar atendimento às demandas dos consumidores, na exata medida de suas disponibilidades de estoque, e, ainda, de conformidade com os usos e costumes: 


\section{CONCLUSÃO}

O instituto da responsabilidade civil é um dos aspectos mais relevantes no Direito Civil, por seu papel social na proteção de bens jurídicos de cunho patrimonial e extrapatrimonial, contribuindo para a ordem e pacificação social, possuindo fundamentação específica na legislação brasileira, tanto na Constituição Federal (artigo $5^{\circ}$, incisos $\mathrm{V}$ e X) como na legislação infraconstitucional, nos artigos 186, 187, 389390 e 391 do Código Civil, e nos artigo 6, inciso VI e 14 do Código de Defesa do Consumidor.

Trata-se de um dever jurídico secundário que surge com o descumprimento de uma obrigação primária que gera um dano. Sempre decorrente de um ato ilícito ou de abuso de direito a responsabilidade civil pode ser decorrente de um contrato ou negócio jurídico entre as partes (contratual) ou instituída pela própria legislação (extracontratual ou aquiliana). Em regra, a responsabilidade civil pressupõe a existência de uma conduta humana (comissiva ou omissiva), da culpa lato sensu (dolo ou culpa stricto sensu), de um dano e do nexo de causalidade entre a conduta e o dano.

A depende da necessidade ou não de comprovação da culpa lato sensu do autor do nado, a responsabilidade civil pode ser classificada ainda em objetiva e subjetiva. A primeira é apurada independentemente da comprovação da culpa lato sensu, ao passo que na segunda a referida culpa necessita ser demonstrada para que haja responsabilização.

A regulamentação da atuação profissional da educação física nas últimas décadas, com a Lei n 9.696/98 e as determinações do Conselho Federal de Educação Física (CONFEF) e dos Conselhos Regionais de Educação Física (CREFs), a exemplo da Resolução no 307/2015 do CONFEF (Código de Ética dos Profissionais de Educação Física), demonstram a preocupação pelo exercício responsável por parte de educadores físicos, no sentido de serem preparados de maneira adequada, gerando resultados mais eficientes e diminuindo riscos decorrentes de má supervisão ou execução dos exercícios físicos.

Para que se configure a necessidade de reparação decorrente da responsabilidade civil, é preciso observar se a conduta envolvida se encaixa nos principais pressupostos da responsabilidade civil, que são: a conduta humana positiva ou negativa, a culpa em sentido amplo, o nexo de causalidade e o dano ou prejuízo causado.

Em grande parte dos casos a atividade desenvolvida pelo personal trainer configura uma relação jurídica de consumo, pois verifica-se a presença de todos os elementos que a constitui, sendo o educar físico (ou a academia) considerado fornecedor, quando presta seu serviço no mercado mediante remuneração, a uma pessoa física que o recebe na qualidade de consumidora.

O profissional da educação física que exerce a função de personal trainer pode atuar como profissional liberal, sem vinculação a nenhuma academia, ou como empregado ou simplesmente prestador de serviço em nome de uma academia. No primeiro caso ele será responsabilizado subjetivamente (mediante a verificação de culpa lato sensu) nos termos do artigo $14, \S 4^{\circ}$ do Código de Defesa do Consumidor. No segundo caso, a academia será responsabilizada objetivamente (independentemente da existência de dolo ou culpa stricto sensu), nos termos do artigo 14, caput do mesmo Código. 
O exame da jurisprudência permitiu perceber que ainda há divergência entre julgadores no que diz respeito à configuração da relação jurídica de consumo na atividade de prestação de serviço do personal trainer, especialmente na qualidade de profissional liberal. Entretanto, superando essa discussão, é pacífico o entendimento acerca da sistemática de responsabilização do referido profissional a depender da forma pela qual ele desenvolve suas atividades, de maneira independente como profissional liberal ou vinculada a uma academia ou instituição análoga.

A compreensão acerca das maneiras pelas quais se caracteriza e se configura a responsabilidade civil do personal trainer contribui para a proteção e defesa dos consumidores, de maneira imediata, pela aplicação da legislação civil-consumerista com fundamento constitucional, e de maneira mediata, na busca pela manutenção da ordem e pacificação social.

\section{REFERENCIAS}

ALMEIDA, Marco Antonio Bettine de; GUTIERREZ, Gustavo Luis Gutierrez. A regulamentação da profissão de Educação Física no Brasil: aspectos legais. Revista EFDeportes. Buenos Aires - Ano 12 n 118 - março de 2008. Disponível em: http://www.efdeportes.com/efd118/a-regulamentacao-da-pofissao-de-educacao-fisica-no-brasil-aspectos-legais.htm. Acesso em: 19 set. 2018.

ALMEIDA, Marco Antônio B. et. al. A responsabilidade civil do profissional de educação física: interpretação jurídica das ações profissionais à luz do direito positivo. Revista EFDeportes. Buenos Aires - Ano 11 - n 106 - março de 2007. Disponível em: http://www.efdeportes.com/efd106/a-responsabilidade-civil-do-profissional-de-educacao-fisica.htm. Acesso em: 21 set. 2018.

BISTENE, Mayra Elisa Barosi. A responsabilidade civil do profissional de Educação Física. Trabalho de Conclusão de Curso (Licenciatura em Educação Física). Universidade Estadual de Campinas. Campinas, 2009.

BRASIL. (Constituição 1988). Constituição da República Federativa do Brasil. Promulgada em 05 de outubro de 1988.

BRASIL. Lei n 8. 078, de 11 de setembro de 1990. Dispõe sobre a proteção do consumidor e dá outras providências.

BRASIL. Lei Federal n 9.696, de 1 de setembro de 1998. Dispõe sobre a regulamentação da Profissão de Educação Física e cria os respectivos Conselho Federal e Conselhos Regionais de Educação Física.

BRASIL. Lei Federal no 10.406, de 10 de janeiro de 2002. Institui o Código Civil.

CONFEF - Conselho Federal de Educação Física. Carta Brasileira de Educação Física. Rio de Janeiro, 2000.

CONFEF. Regulamentação da Educação Física no Brasil. Disponível em: http://www.confef.org.br/confef/conteudo/16. Acesso em: 20 set. 2018.

CONFEF. Resolução n 45/2002. Dispõe sobre o registro de não-graduados em Educação Física no Sistema CONFEF/CREFs. Rio de Janeiro, 18 de fevereiro de 2002.

CONFEF. Resolução $n^{\circ}$ 46/2002. Dispõe sobre a Intervenção do Profissional de Educação Física e respectivas competências e define os seus campos de atuação profissional. Rio de Janeiro, 18 de fevereiro de 2002.

CONFEF. Resolução n 307/2015. Dispõe sobre o Código de Ética dos Profissionais de Educação Física registrados no Sistema CONFEF/CREFs. Rio de Janeiro, de 9 de novembro de 2015.

DINIZ, Maria Helena. Curso de direito civil brasileiro: responsabilidade civil. 31. ed. São Paulo: Saraiva, 2017. v. 7. GONÇALVES, Carlos Roberto. Direito civil brasileiro: responsabilidade civil. 13. ed. São Paulo: Saraiva Educação, 2018. v. 4 
GONÇALVES, Carlos Roberto. Direito civil: esquematizado: responsabilidade civil, direito de família, direito das sucessões. 4. ed. São Paulo: Saraiva, 2017. v. 3.

FARIAS, Cristiano Chaves de; ROSENVALD, Nelson; BRAGA NETTO, Felipe Peixoto. Curso de Direito Civil: responsabilidade civil. 4. ed. Salvador: JusPodivm, 2017.

FILOMENO, José Geraldo Brito. Direitos do consumidor. 15. ed. São Paulo: Atlas, 2018.

FRANÇA, Rubens Limongi. Enciclopédia saraiva de Direito. São Paulo: Saraiva, 1977.

FREIRE, Elisabete dos Santos; VERENGUER, Rita de Cássia G.; COSTA REIS, Marise Cisneiros. Educação Física: pensando a profissão e a preparação profissional. Revista Mackenzie de Educação Física e Esporte. 2002, 1(1):39-46. GAGLIANO, Pablo Stolze; PAMPLONA FILHO, Rodolfo. Novo curso de direito civil: responsabilidade civil. 10. ed. São Paulo: Saraiva, 2012. v. 3.

Instituto Nacional de Estudos e Pesquisa Educacional Anísio Teixeira (INEP). Sinopses Estatísticas da Educação Superior - Graduação. Disponível em: http://portal.inep.gov.br/web/guest/sinopses-estatisticas-da-educacao-superior. Acesso em: 21 set. 2018.

MARTINS-COSTA, Judith. Comentários ao novo Código Civil. Do inadimplemento das Obrigações. TEIXEIRA, Sálvio de Figueiredo (Coord.). Rio de Janeiro: Forense, 2003.

MELLO GUERRA, Alexandre Dartanhan de; BENACCHIO, Marcelo (Org.). Responsabilidade Civil. São Paulo: Escola Paulista de Magistratura, 2015.

OLIVEIRA, Edson Eduardo Rodrigues de. A importância da regulamentação da profissão de educação física para uma categoria profissional: O caso de Minas Gerais. Dissertação (Mestrado em gestão Esportiva). Faculdade de Desporto da Universidade do Porto. Porto, 2017.

OLIVEIRA, Aurélio Luiz de; Silva, Marcelo Pereira da. O profissional de educação física e a responsabilidade legal que o cerca: Fundamentos para uma discussão. Artigo científico - IX Simpósio Internacional de Processo Civilizador - Ponta Grossa/PR, 2005.

OLIVEIRA, Juliana Andrade Padilha de. Responsabilidade civil do profissional de educação física. Trabalho de Conclusão de Curso (Bacharelado em Educação Física). Universidade Tecnológica Federal do Paraná. Curitiba, 2015.

PARANÁ, TRIBUNAL DE JUSTIÇA DO (TJPR). Recurso Inominado: RI 001710003201381600301 PR $001700-$ 03.2013.8.16.0030/1 (Acórdão). Recorrente: Tânia Marta Moreira de Abreu. Recorrido: Cleverson Acordi. Relator: Leo Henrique Furtado Araújo. Curitiba, 3 de dezembro de 2015.

PEREIRA, Caio Mário da Silva. Responsabilidade Civil. De Acordo com a Constituição de 1988. 5. ed. Rio de Janeiro: Forense, 1994.

PEREIRA, C. M. Instituições de Direito Civil. Educação Física. Forense, 1976. v. III

SANTA CATARINA, TRIBUNAL DE JUSTIÇA DE (TJSC). Apelação Cível: AC 20140216912 SC 2014.021691-2 (Acórdão). Apelante: Carlos Alberto Emke. Apelado: Academia de Ginástica Viva a Vida. Relator: Trindade dos Santos. Florianópolis, 25 de junho de 2014.

SILVA, Carlos Alberto Figueiredo. Educação Física e registro profissional. Motriz, Rio Claro, v. 18 n. 3, p.615-626, jul./set. 2012.

SOUSA NETO, S. et. al. A formação do profissional de Educação Física no Brasil: uma história sob a perspectiva da legislação federal no século XX. Rev. Bras. Cienc. Esporte, Campinas, v. 25, n. 2, p. 113-128, jan. 2004.

TARTUCE, Flavio. Manual de direito civil: volume único. 7. ed. Rio de Janeiro: Forense; São Paulo: Método, 2017.

Recebido/Received: 07.02.2020.

Aprovado/Approved: 21.05.2020. 